\title{
Electrochemical Energy Storage Applications of CVD Grown Niobium Oxide Thin Films
}

\author{
Raquel Fiz ${ }^{1}$, Linus Appel ${ }^{1}$, Antonio Gutiérrez-Pardo ${ }^{1,2}$, Joaquín Ramírez-Rico ${ }^{2}$, and Sanjay Mathur ${ }^{1, *}$ \\ ${ }^{1}$ Institute of Inorganic Chemistry, University of Cologne, Greinstraße 6, 50939, Cologne, Germany \\ ${ }^{2}$ Departamento Fisica de la Materia Condensada-ICMS (Universidad de Sevilla-CSIC) Avda Reina Mercedes s/n, 41012 \\ Seville, Spain
}

\begin{abstract}
We report here on controlled synthesis, characterization and electrochemical properties of different polymorphs of niobium pentoxides grown by CVD of new single-source precursors. $\mathrm{Nb}_{2} \mathrm{O}_{5}$ films deposited at different temperatures showed sys-

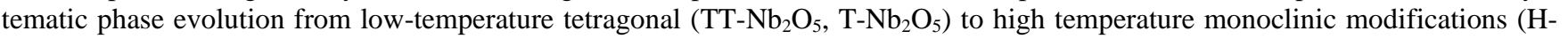
$\mathrm{Nb}_{2} \mathrm{O}_{5}$ ). Optimization of the precursor flux and substrate temperature enabled phase-selective growth of $\mathrm{Nb}_{2} \mathrm{O}_{5}$ nanorods and films on conductive mesoporous biomorphic carbon matrices (Bio-C). $\mathrm{Nb}_{2} \mathrm{O}_{5}$ thin films deposited on monolithic mesoporous biomorphic carbon (Bio-C) scaffolds produced composite materials integrating the high surface area and conductivity of carbonaceous matrix with the intrinsically high capacitance of nanostructured niobium oxide. Hetero-junctions in $\mathrm{Nb}_{2} \mathrm{O}_{5} / \mathrm{BioC}$ composites were found to be beneficial in electrochemical capacitance. Electrochemical characterization of $\mathrm{Nb}_{2} \mathrm{O}_{5} / \mathrm{BioC}$ composites showed that small amounts of $\mathrm{Nb}_{2} \mathrm{O}_{5}$ (as low as 5\%) in conjunction with Bio-C resulted in a seven-fold increase in the electrode capacitance, from 15 to $104 \mathrm{~F} \mathrm{~g}^{-}$ ${ }^{1}$, making these materials ideally suited for electrochemical energy storage applications.
\end{abstract}

\section{INTRODUCTION}

$\mathrm{Nb}_{2} \mathrm{O}_{5}$ is one of the most popular transparent oxide semiconductors with a band gap $\left(\mathrm{E}_{\mathrm{g}}\right)$ of $3.2 \mathrm{eV}$ which shows an excellent chemical stability and corrosion resistance in both acidic and alkaline media, and exhibits band levels close to water redox potentials. Therefore, it has been discussed as a promising alternative material to $\mathrm{TiO}_{2}$ in several applications. For instance, niobium-based materials are presently of significant interest in the field of catalysis ${ }^{1-3}$, gas sensing ${ }^{4-7}$, electrochromism ${ }^{8}$ and dye sensitized solar cells (DSSCs) ${ }^{9-12}$. Recent reports include the integration of $\mathrm{Nb}_{2} \mathrm{O}_{5}$ in electrode materials in supercapacitor applications, which has resulted in excellent performances ascribed to the pseudocapacitance effect involved. ${ }^{13-15}$

However, the niobium-oxygen system is particularly complex, as narrow deviations from the exact stoichiometry in $\mathrm{Nb}_{2} \mathrm{O}_{5}$ strongly affect the physical properties of the material. For instance, a small oxygen deficiency leads to the transition from insulating to n-type semiconducting behavior ${ }^{9}$. Niobium oxide films have been prepared by different methods including magnetron sputtering ${ }^{15}$, electrodeposition and anodization ${ }^{16}$, thermal oxidation ${ }^{17}$, sol-gel methods ${ }^{18-22}$, chemical vapor deposition $(C V D)^{23}$ or atomic layer epitaxy ${ }^{24}$. One-dimensional nanostructures typically exhibit enhanced charge transport properties due to their anisotropy and thus are very interesting from the device point of view. Despite their proming technological potential, the synthesis of one-dimensional $\mathrm{Nb}_{2} \mathrm{O}_{5}$ nanostructures has been limited to polycrystalline $\mathrm{Nb}_{2} \mathrm{O}_{5}$ nanofibers by electrospinning ${ }^{25}, \mathrm{Nb}_{2} \mathrm{O}_{5}$ nanopores by electrochemical synthesis ${ }^{26,27}, \mathrm{Nb}_{2} \mathrm{O}_{5}$ nanowire films grown by thermal oxidation of niobium foils ${ }^{28}$, and the hydrothermal synthesis of $\mathrm{Nb}_{2} \mathrm{O}_{5}$ nanorods ${ }^{29}$ and nanobelts. ${ }^{30}$ Among all these methods, CVD is of special interest to achieve scalable coatings on substrates with different morphologies. However, the current precursors used for the fabrication of $\mathrm{Nb}_{2} \mathrm{O}_{5}$ and the controlled growth of high crystalline niobium oxide nanorods by this technique are limited. Therefore, the development of suitable precursors to obtain $\mathrm{Nb}_{2} \mathrm{O}_{5}$ with the desired properties needs further attention.

We recently reported on the humidity sensing properties of $\mathrm{Nb}_{2} \mathrm{O}_{5}$ nanorods synthesized by chemical vapor deposition of niobium iso-propoxide. ${ }^{5}$ In the present work we investigate the properties of different polymorphs of $\mathrm{Nb}_{2} \mathrm{O}_{5}$ thin films obtained at different substrate temperatures, and extend their synthesis to lower CVD temperatures by using monomeric Nb precursors with enhanced volatility and stability. Furthermore, we demonstrate the potential of gas-phase deposition to obtain homogeneously coated complex hierarchical porous structures due to penetration of precursor flux in all parts of a matrix. Specifically, biomorphic carbon obtained by pyrolysis of wood at high temperatures was used as mesoporous scaffold with open and interconnected porosity. The $\mathrm{Nb}_{2} \mathrm{O}_{5} /$ BioCarbon composites were tested as electrode materials in electrochemical energy storage applications. 


\section{EXPERIMENTAL}

Synthesis of $\mathbf{N b}_{2} \mathbf{O}_{5}$ Thin Films: Dimeric Niobium(V)iso-propoxide [compound $\mathbf{1}, \mathrm{Nb}_{2}\left(\mathrm{O}^{i} \mathrm{Pr}\right)_{10}$ ] and monomeric tera-iso-propoxy-(1,1,1-trifluoro-3-(2-pyridyl)propen2-olate)niobium(V) [compound $2, \quad \mathrm{Nb}\left(\mathrm{O}^{i} \mathrm{Pr}\right)_{4}\left(\mathrm{C}_{8} \mathrm{H}_{5} \mathrm{NOF}_{3}\right)$ ] were prepared in a modified Stock vacuum line under an inert atmosphere of nitrogen according to a previously reported procedure, ${ }^{31}$ and used as single-source precursor in a low-pressure chemical vapor deposition reactor described elsewhere. ${ }^{32}$ The synthesis of $\mathrm{Nb}_{2} \mathrm{O}_{5}$ thin films was performed in a horizontal CVD reactor, in which the substrate of interest was attached onto a graphite holder which was inductively heated by a highfrequency generator under dynamic vacuum. The molecular precursors were introduced in the reactor chamber by heating the precursor reservoir to the chosen temperature to bring them into the gas phase (sublimation points of $70^{\circ} \mathrm{C}$, and $50^{\circ} \mathrm{C}$ under $\sim 10^{-4} \mathrm{mbar}$, for precursors $\mathbf{1}$, and $\mathbf{2}$, respectively), where the precursor flux was regulated by monitoring the pressure in the reactor chamber. $\mathrm{Nb}_{2} \mathrm{O}_{5}$ thin films were deposited at the temperature range between $500-1000^{\circ} \mathrm{C}$ during a deposition time of 30 minutes on silicon, alumina, and BioC substrates.

Synthesis of Biomorphic Carbons (BioC): Synthesis of monolithic macroporous carbon materials obtained from cellulosic precursors was performed according to a previously reported method. ${ }^{33}$ Beech (Fagus silvatica) precursors were chosen as prototypical natural and recyclable wood products. Samples were first cut into $(75 \times 10 \times 10) \mathrm{mm}^{3}$ pieces and dried thoroughly in an oven. Pyrolysis was then performed in flowing $\mathrm{N}_{2}$ in a tube furnace with a ramp rate of $1^{\circ} \mathrm{C} \mathrm{min}{ }^{-1}$ up to $500{ }^{\circ} \mathrm{C}$ and then at $5^{\circ} \mathrm{C} \min ^{-1}$ to $1000{ }^{\circ} \mathrm{C}$ temperature, while cooling was performed at a rate of $5{ }^{\circ} \mathrm{C} \mathrm{min}{ }^{-1}$ (in order to avoid cracks in the material). The pieces were cut with a diamond blade leading to macroporous carbonaceous substrates with a cross section of $1 \mathrm{~cm}^{2}$ and thickness of $1 \mathrm{~mm}$.

Structural and Compositional Characterization: Thermogravimetric and differential thermal analysis were carried out on a METTLER Toledo TGA/DSC STARe System for two purposes: first, to determine the thermal properties of the precursors such as melting and decomposition points, and second, to estimate the amount of active mass in the $\mathrm{Nb}_{2} \mathrm{O}_{5} / \mathrm{BioC}$ composites in the electrochemical characterization.

Scanning electron microscopy (SEM) was performed in an FE-SEM FEI 430 Nova NanoSEM system equipped with an energy-dispersive $\mathrm{X}$-ray spectrometer (Apollo $\mathrm{X}$ by EDAX). Atomic Force Microscopy (AFM) was performed in tapping mode in a XE-100 ParkSystem equipped with a 910ACTA cantilever for topographical characterization of the $\mathrm{Nb}_{2} \mathrm{O}_{5}$ films deposited from decomposition of compounds $\mathbf{1}$ and $\mathbf{2}$, respectively at the same process temperature. High Resolution Transmission Electron Microscopy (HR-TEM) was performed in a Jeol JEM2010F field emission gun microscope with a $0.19 \mathrm{~nm}$ point-to-point resolution at the University of Barcelona. TEM samples were prepared by mechanical flat polishing up to $20 \mu \mathrm{m}$ thickness and subsequent low angle (5 $5^{\circ} \mathrm{Ar}^{+}$ion milling until electron transparency.

The crystal structures of the obtained samples were studied by means of X-ray diffraction (XRD), operating in Bragg-Brentano mode (XRD Stoe Stadi MP vertical diffractometer with $\mathrm{Cu} \mathrm{K} \alpha$; source $(\lambda=154.18 \mathrm{pm}))$.
X-Ray photoelectron spectroscopy analysis was performed in a Surface Science (SSI) ESCA M-Probe operating with AlK $\alpha$ monochromatic radiation $(1486 \mathrm{eV})$ at a resolution of $0.8 \mathrm{eV}$.

Nuclear Magnetic Resonance (NMR) spectra were recorded on a Bruker Avance II 300 spectrometer $\left({ }^{1} \mathrm{H}\right.$ at $300.13 \mathrm{MHz}$, ${ }^{13} \mathrm{C}$ at $75.02 \mathrm{MHz}$ and ${ }^{19} \mathrm{~F}$ at $282.45 \mathrm{MHz}$, BBI probe with Zgradient) at ambient temperature or on a Bruker AV $400\left({ }^{1} \mathrm{H}\right.$ at $400.13 \mathrm{MHz},{ }^{13} \mathrm{C}$ at $100.61 \mathrm{MHz}$ and ${ }^{19} \mathrm{~F}$ at $376.50 \mathrm{MHz}, \mathrm{H}, \mathrm{F}$, $\mathrm{X}$ TBI probe with Z-gradient) at low temperatures. Chemical shifts for ${ }^{1} \mathrm{H}$ and ${ }^{13} \mathrm{C}$ NMR shifts are reported using tetramethylsilane (TMS) as external standard and ${ }^{19} \mathrm{~F}$ spectra were measured using $\mathrm{CCl}_{3} \mathrm{~F}$ as external standard. In situ mass spectrometry was performed using a Pfeiffer QMG 220 setup, which was attached directly to the exhaust of the CVD reaction chamber.

Electrochemical Properties: In order to measure the electrochemical properties of $\mathrm{Nb}_{2} \mathrm{O}_{5} / \mathrm{BioC}$ ohmic electrical contacts were fabricated by embedding copper wire in the carbonaceous substrate and fixing with silver paste, and subsequently coating the back side with non-transparent and non-conducting epoxy resin. The electrochemical response was investigated in a three electrode configuration, by using $\mathrm{Ag} / \mathrm{AgCl}$ (sat. $\mathrm{KCl} 3 \mathrm{M}$, $+0.197 \mathrm{~V}$ vs. ENH) as the reference electrode, Pt as the counter electrode, and $1 \mathrm{M} \mathrm{KOH}$ as the electrolyte. Measurements were performed in an EDAQ ERZ-101 Advanced Electrochemistry System. Cyclic voltammetry in the voltage window of -1 to $0 \mathrm{~V}$ was measured to evaluate the supercapacitor behavior at room temperature and at varying scan rates (between 1 and $30 \mathrm{mV} \mathrm{s}$ $\left.{ }^{1}\right)$.

\section{RESULTS AND DISCUSSION}

Dimeric and Monomeric Nb CVD Precursors: Figure 1 shows the molecular compounds chosen as single source precursor for deposition of $\mathrm{Nb}_{2} \mathrm{O}_{5}$ thin films via chemical vapor deposition. In previous works we showed that the stability of metal alkoxides can be modulated by the introduction of $\beta$ $N$-donoralkenolate ligands, which allows the synthesis of compounds with lower tendency towards oligomerization. ${ }^{31,34,35} \mathrm{In}$ this work, the performance of dimeric $\mathrm{Nb}_{2}\left(\mathrm{O}^{\mathrm{i}} \mathrm{Pr}\right)_{10}$ and monomeric $\mathrm{Nb}\left(\mathrm{O}^{\mathrm{i}} \mathrm{Pr}\right)_{4}\left(\mathrm{C}_{8} \mathrm{H}_{5} \mathrm{NOF}_{3}\right)$ as suitable precursors for CVD applications is tested and compared.
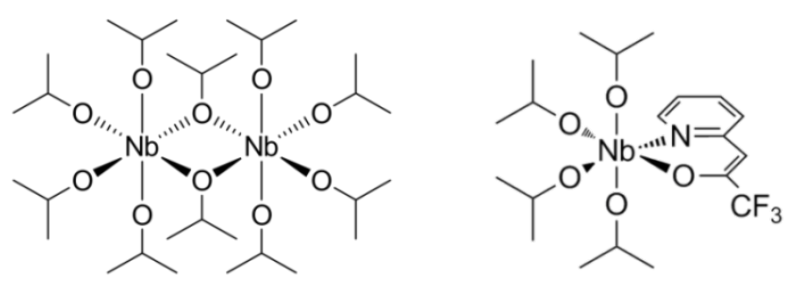

Figure 1. Molecular structures of $\mathrm{Nb}_{2}\left(\mathrm{O}^{i} \mathrm{Pr}\right)_{10} \quad 1$ (left) and $\mathrm{Nb}\left(\mathrm{O}^{i} \mathrm{Pr}\right)_{4}\left(\mathrm{C}_{8} \mathrm{H}_{5} \mathrm{NOF}_{3}\right) 2$, (right).

The volatility and stability of the Nb sources was first investigated by thermogravimetric and simultaneous differential scanning calorimetry analysis (TG/DTA) under a nitrogen atmosphere (see Figure 2). Endothermic features at $80{ }^{\circ} \mathrm{C}$ and $69^{\circ} \mathrm{C}$ are ascribed to the melting points of $\mathrm{Nb}_{2}\left(\mathrm{O}^{i} \mathrm{Pr}\right)_{10}(\mathbf{1})$ and $\mathrm{Nb}\left(\mathrm{O}^{i} \mathrm{Pr}\right)_{4}\left(\mathrm{C}_{8} \mathrm{H}_{5} \mathrm{NOF}_{3}\right)$ (2), respectively. The lower melting point of $\mathbf{2}$ in the DTA curve may be seen as an evidence for an enhanced vapor pressure compared to the homoleptic alkoxide derivative $\mathbf{1}$. The monomeric nature of compound $\mathbf{2}$ is already 
an argument for the improved stability in comparison to the dimeric structure of $\mathbf{1}$. However, the clear two-step exothermic decomposition which completes at $350{ }^{\circ} \mathrm{C}$ in contrast to the $250{ }^{\circ} \mathrm{C}$ needed for compound $\mathbf{1}$ is further evidence. A more detailed analysis of the weight loss curve reveals that the ligand is released as a whole unit. The higher stability is associated to the electron-back-donating nitrogen atom and the effective steric shielding of the six coordinated metal center, which also lowers the tendency towards oligomerization. The observed weight losses are in all cases very close to theoretical values (see Table 1) and small deviation are ascribed to residual contamination due to the possible incorporation of carbon.

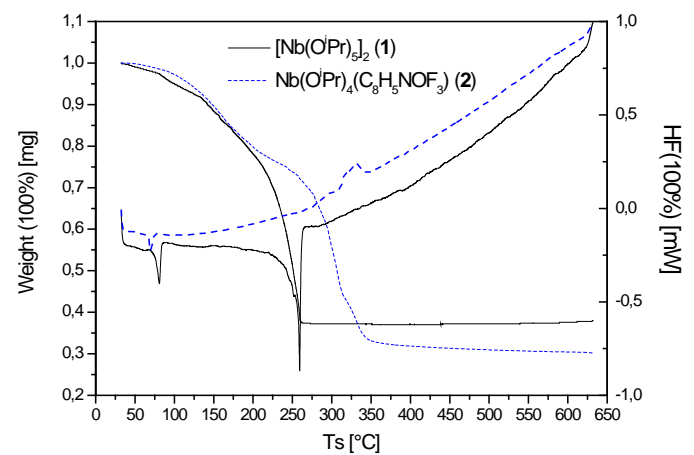

Figure 2. TG/DTA analysis of $\mathrm{Nb}_{2}\left(\mathrm{O}^{i} \mathrm{Pr}\right)_{10}(1)$ and $\mathrm{Nb}\left(\mathrm{O}^{\mathrm{i}} \mathrm{Pr}\right)_{4}\left(\mathrm{C}_{8} \mathrm{H}_{5} \mathrm{NOF}_{3}\right)(2)$.

Table 1. Calculated and measured mass loss during decomposition processes of the used precursors analyzed by TG/DTA measurements.

\begin{tabular}{ccc} 
Mass Loss & Calculated & Measured \\
\hline $\mathrm{Nb}_{2}\left(\mathrm{O}^{i} \mathrm{Pr}\right)_{10}(\mathbf{1})$ & $34.26 \%$ & $35.01 \%$ \\
$\mathrm{Nb}\left(\mathrm{O}^{\mathrm{i} P r}\right)_{4}\left(\mathrm{C}_{8} \mathrm{H}_{5} \mathrm{NOF}_{3}\right)(\mathbf{2})$ & $25.71 \%$ & $28.23 \%$ \\
$\left(\mathrm{C}_{8} \mathrm{H}_{6} \mathrm{NOF}_{3}\right)(\mathbf{L})$ & $18.20 \%$ & $19.00 \%$
\end{tabular}

Chemical Vapor Deposition and Thin Film Characterization: Both compounds were used as single-source precursors in a horizontal CVD reactor at different substrate temperatures (400-1000 ${ }^{\circ} \mathrm{C}$ ) on different substrates ( $\mathrm{Si}, \mathrm{Al}_{2} \mathrm{O}_{3}$ and BioC). Although incomplete decomposition of the precursor molecules often results in carbon contamination, EDX revealed CVD deposits to be free of carbon independently of the precursor chosen. Furthermore, no significant differences were observed in the XPS analysis, which reveals the unique presence of $\mathrm{Nb}(\mathrm{V})$ species, and XRD analysis exhibits similar diffractograms independently of the precursor used. The films show as well similar morphologies; AFM in tapping mode of the $\mathrm{Nb}_{2} \mathrm{O}_{5}$ films deposited at $500{ }^{\circ} \mathrm{C}$ from decomposition of both precursors illustrate analogous topological and roughness features (see comparison in supporting information S1, S2, S3). As the precursor source does not seem to have a significant effect in the properties of the deposits obtained, the influence of substrate temperature and precursor feedstock on the crystallization process of the niobium oxide films was further investigated.

Figure 3 shows SEM images of $\mathrm{Nb}_{2} \mathrm{O}_{5}$ thin films deposited on silicon substrates by CVD at temperatures comprised between $500-1000^{\circ} \mathrm{C}$. Homogeneous and uniform coverage of the substrates was observed in all cases, and the morphology and crystallinity are influenced by the substrate temperature. At lower temperatures, the films show small spherical grains with an average diameter of $18 \pm 2 \mathrm{~nm}$. At high temperatures columnar growth was observed, in which adatom-adatom interactions are stronger than those between adatom-surface, leading to the formation of clusters growing in preferential directions. $\mathrm{Nb}_{2} \mathrm{O}_{5}$ nanorods with diameters of $50 \pm 12 \mathrm{~nm}$ were observed at higher substrate temperatures.

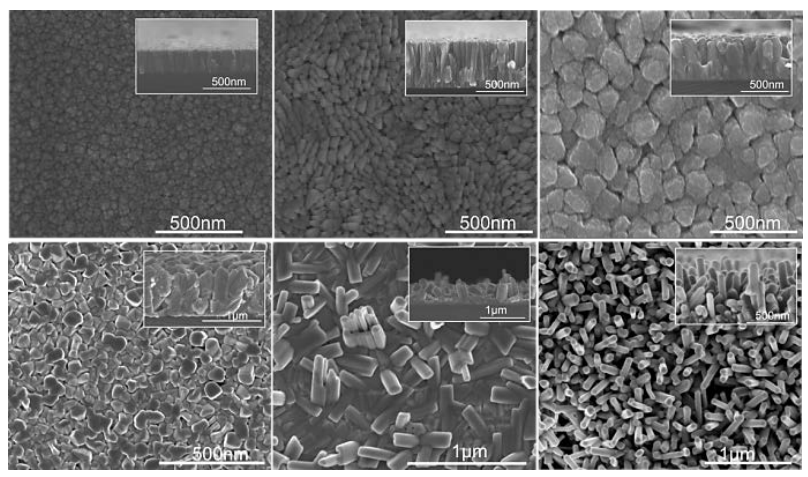

Figure 3. SEM micrograph of nanostructured $\mathrm{Nb}_{2} \mathrm{O}_{5}$ thin films deposited at different substrate temperatures in the range from 500 $1000{ }^{\circ} \mathrm{C}$ ); Inset represents the cross section of the films in order to estimate their thicknesses.

Figure 4 displays the $\mathrm{Nb} 3 \mathrm{~d}$ core level spectra of the $\mathrm{NbO}_{5}$ thin films deposited at different substrate temperatures measured by XPS. As expected, the most thermodynamically stable phase of niobium oxide was found in all cases with small deviation in the binding energies. These minor deviations could be correlated to disorder and intrinsic defects of the crystalline structure, which are most likely related to the number of valence electrons at the material's surface. GI-XRD measurements shown in Figure 4 reveal the evolution from amorphous thin films at $400^{\circ} \mathrm{C}$ to the low temperature phases of $\mathrm{Nb}_{2} \mathrm{O}_{5}$ : pseudohexagonal (TT- $\mathrm{Nb}_{2} \mathrm{O}_{5}$, JCPDS 28-0317) and orthorhombic ( $T$ $\mathrm{Nb}_{2} \mathrm{O}_{5}$, JCPDS 30-0873) at $500{ }^{\circ} \mathrm{C}$ and higher. However, due to the similarity of the diffraction patterns (shown in Supporting Information S4) it is not possible to distinguish them. The main difference lies in the broadening of the peaks in the TT- $\mathrm{Nb}_{2} \mathrm{O}_{5}$, while there is a clear split of the peaks in the more crystalline, lower symmetry $\mathrm{T}-\mathrm{Nb}_{2} \mathrm{O}_{5}$ phase. Above $900{ }^{\circ} \mathrm{C}$ the main $\mathrm{Nb}_{2} \mathrm{O}_{5}$ phase shifts to one of the high-temperature variants: tetragonal $\left(M-\mathrm{Nb}_{2} \mathrm{O}_{5}\right.$, JCPDS 30-0872) and monoclinic ( $\mathrm{H}-\mathrm{Nb}_{2} \mathrm{O}_{5}$, JCPDS 80-2493), which was investigated in detail by HR-TEM and reported previously. ${ }^{5}$ Controlling the precursor feedstock, nanorod morphology can be achieved (see details in Supporting Information S5). Interestingly, the only difference in coatings obtained using precursors (1) and (2) was that $\mathrm{Nb}_{2} \mathrm{O}_{5}$ nanorods could be obtained at slightly lower temperatures by decomposition of compound (2). 

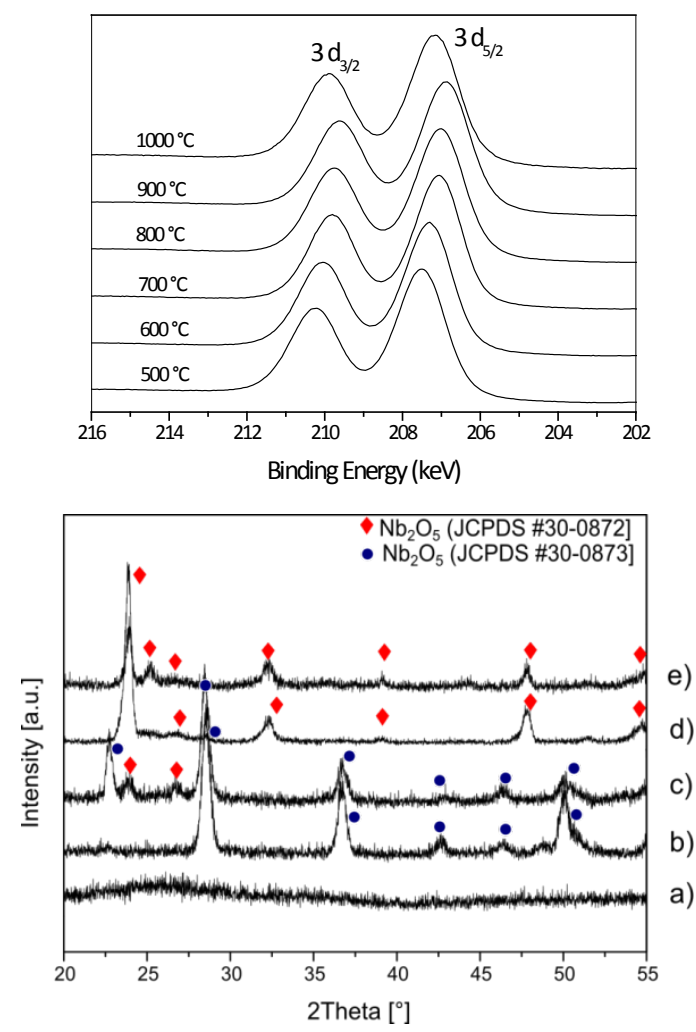

Figure 4. XPS (top) and XRD (bottom) pattern of $\mathrm{Nb}_{2} \mathrm{O}_{5}$ deposited at different decomposition temperatures ranging from amorphous

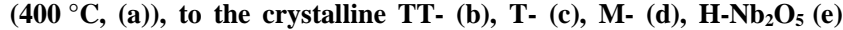
phases (increments of $100^{\circ} \mathrm{C}$ ).

With the purpose of better understanding oriented growth in $\mathrm{Nb}_{2} \mathrm{O}_{5}$, nanorods deposited at high temperatures were further characterized by HR-TEM by investigating their interface with the $\mathrm{Si}$ substrate (Figure 5). A homogeneous $\mathrm{SiO}_{2}$ layer of approximately $2 \mathrm{~nm}$ was observed on top of the silicon substrate, precluding an epitaxial relationship between substrate and overlayer. FFT of HR-TEM images of $\mathrm{Nb}_{2} \mathrm{O}_{5}$ could be indexed according to the monoclinic modification corresponding to space group $C 2 / m$ (\#12). The histogram displays the orientation distribution measured over 40 NRs. A preferential angle of around $60^{\circ}$ with respect to the substrate and a second one at $90^{\circ}$ are found. Other orientations are randomly present which might indicate that preferential growth is due to the crystal structure itself and not due to interaction with the substrate. For a given growth temperature no structural differences among films obtained by precursors (1) or (2) could be observed.

In order to understand the performance of the precursors in the CVD process and their decomposition, a cooling trap was placed right after the reaction chamber where the volatile byproducts formed during the process were condensed. NMR investigations of the thermally activated fragments identified propene, iso-propanol and acetone, expected from $\alpha$-bond cleavage and $\beta$-hydride elimination of coordinated iso-propoxy groups in the thermally activated fragmentation of the alkoxides (see Figure S7). ${ }^{31}$ However, the two-step decomposition process previously observed in the TG/DTA analysis suggested a different decomposition route for compound (2).
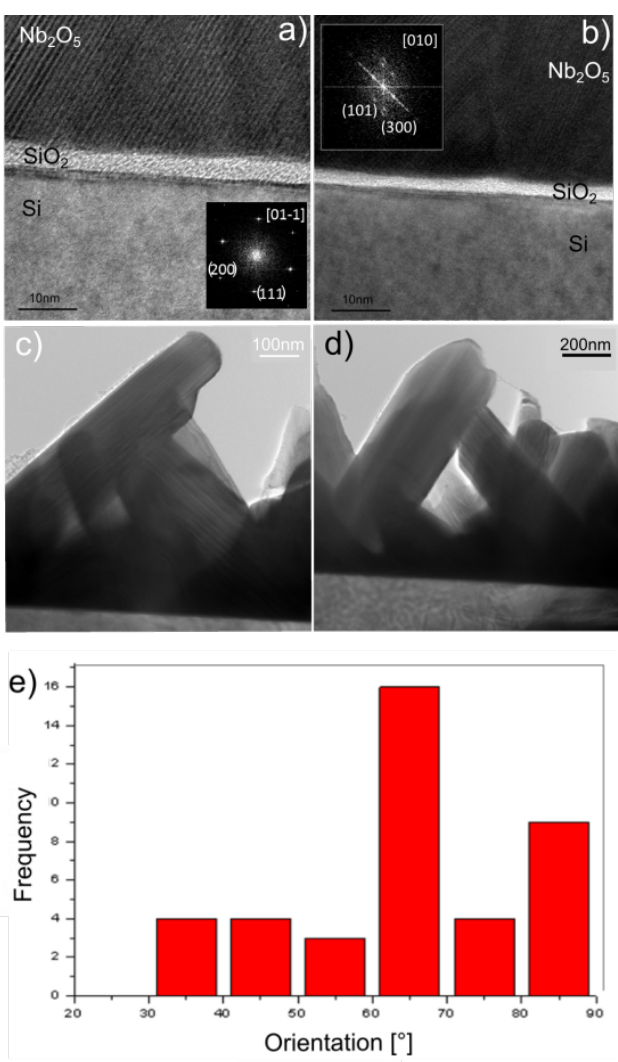

Figure 5. Cross Section HR-TEM of $\mathrm{Nb}_{2} \mathrm{O}_{5}$ nanorods grown at high temperatures in the $\mathrm{N}$ modification form of monoclinic on silicon substrates. Inset shows the FFT analysis. A histogram is shown indicating the orientation of the nanorods.

The fragmentation paths during the chemical vapor deposition process could differ due to thermodynamic and mass transport processes inside the reactor. Therefore, mass spectrometry analysis was further performed in situ during the CVD process to monitor the decomposition of each precursor in the gas phase. Figure 6 displays the mass spectrometry analysis in the range of temperatures from 300 to $800{ }^{\circ} \mathrm{C}$ in steps of $100{ }^{\circ} \mathrm{C}$. Interestingly, similar fragmentation patterns were found for both (1) and (2), which are typical from the decompositions of the iso-propoxy groups (including $\mathrm{H}_{2}{ }^{+}, \mathrm{H}_{2} \mathrm{O}^{+}, \mathrm{C}_{2} \mathrm{H}_{4}{ }^{+}, \mathrm{CO}^{+}, \mathrm{N}_{2}{ }^{+}$, $\mathrm{C}_{3} \mathrm{H}_{5}{ }^{+}, \mathrm{C}_{3} \mathrm{H}_{6} \mathrm{O}^{+}$, and $\left(\mathrm{CH}_{3} \mathrm{OH}\right) \mathrm{CH}_{2}-\mathrm{C}^{+}$traces $)$. The selected area represents decomposition fragments at temperatures above $500{ }^{\circ} \mathrm{C}$, which indicates that precursor 1 starts decomposing at lower temperatures than precursor 2 and evidences the enhanced stability of compound $\mathbf{2}$. These results suggest that the alkenolate ligand could be released as a whole unit above a certain temperature, followed by decomposition of the remaining alkoxide groups in the monomeric molecule. Given the high molecular weight of this compound, it decomposed mostly on the reactor walls close to the chemical vapor reaction and does not reach either the cooling trap or the mass spectrometer, evidenced in the yellowish color acquired by the quartz tube in which the reaction takes place. Estimation of the growth rate of the films also suggests that the growth rate for compound (2) is slightly higher than from compound (1) (see Figure S6). In conclusion, $\mathrm{Nb}_{2} \mathrm{O}_{5}$ thin films with comparable properties were synthesized by CVD of both precursors, although compound (2) exhibited higher stability and improved properties regarding the CVD process. 

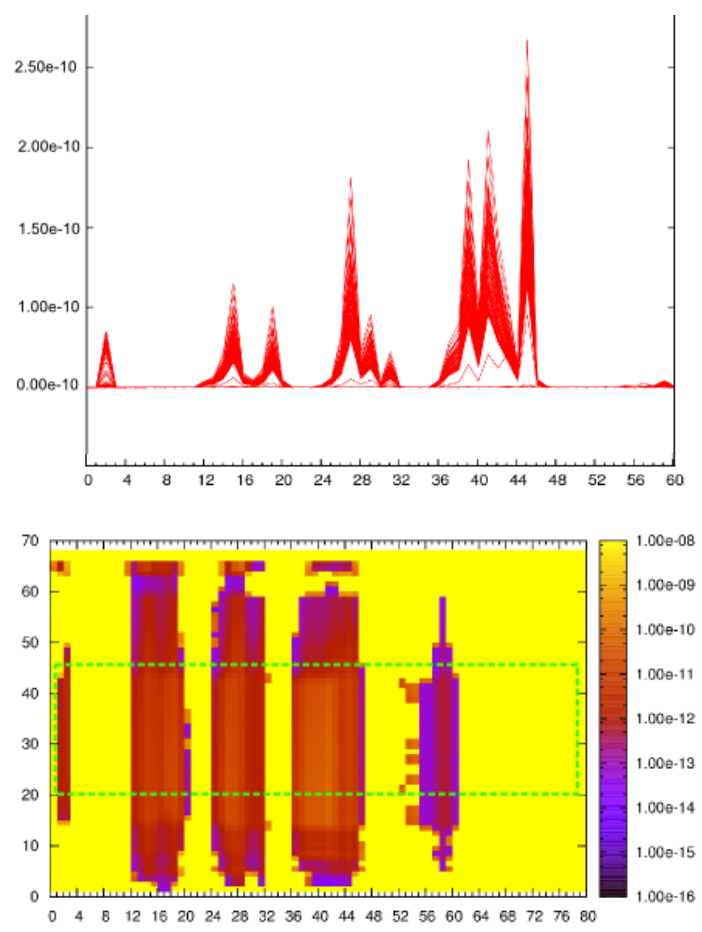
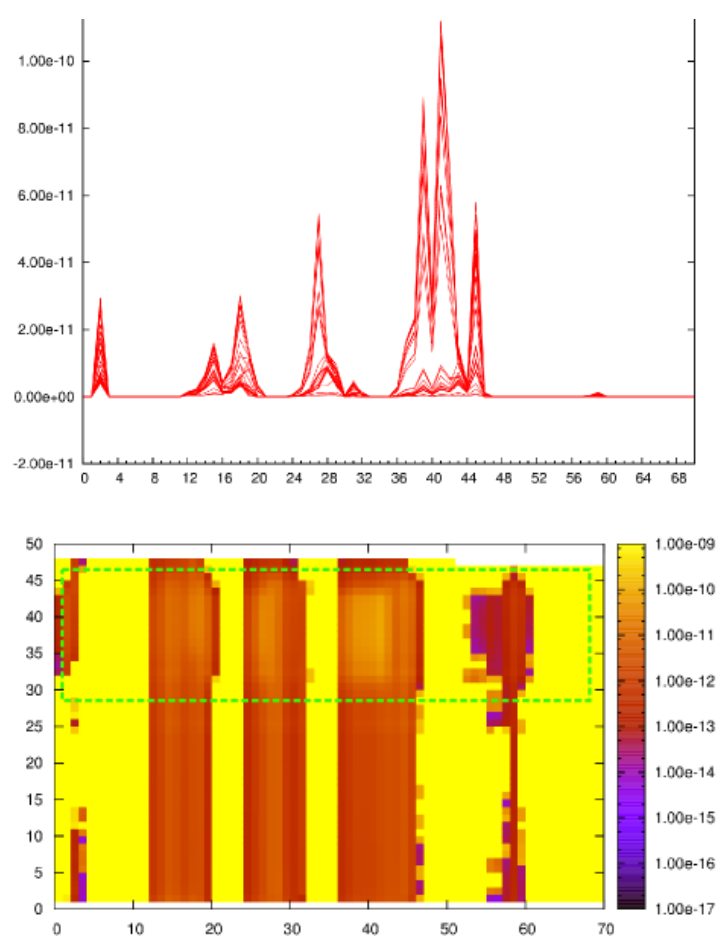

Figure 6. In situ recorded mass spectra during the gas-phase decomposition from room temperature until $800{ }^{\circ} \mathrm{C}$, and cooling back of (left) dimeric $\mathrm{Nb}_{2}\left(\mathrm{O}^{i} \mathrm{Pr}\right)_{10}$, and (right) monomeric $\mathrm{Nb}\left(\mathrm{O}^{i} \mathrm{Pr}\right)_{4}\left(\mathrm{C}_{8} \mathrm{H}_{5} \mathrm{NOF}_{3}\right)$.

Electrochemical Properties of $\mathrm{Nb}_{2} \mathrm{O}_{5}$ Thin Films Synthesized by CVD: Monolithic macroporous wood-derived carbons (BioC) serve as scaffold for the growth of $\mathrm{Nb}_{2} \mathrm{O}_{5}$ thin films with the desired structural properties and offer a promising alternative to the conventional carbonaceous electrode materials used in current electrochemical energy storage applications. Hierarchical meso- and macroporous architectures exhibit high specific areas, large pore volumes as well as open and interconnected porosity, which allows the integration of thin films in more complex systems. Furthermore, the use of this kind of structures in electrochemical energy storage applications eliminates the need of binders and conductive additives normally required in the typical slurry preparation for the fabrication of suitable electrode materials. The porous structure also allows a better diffusion of the electrolyte within the material, which also improves the kinetic mechanisms involved. Figure 7 shows the SEM of the $\mathrm{Nb}_{2} \mathrm{O}_{5}$ deposits on BioC substrates at different substrate temperatures.
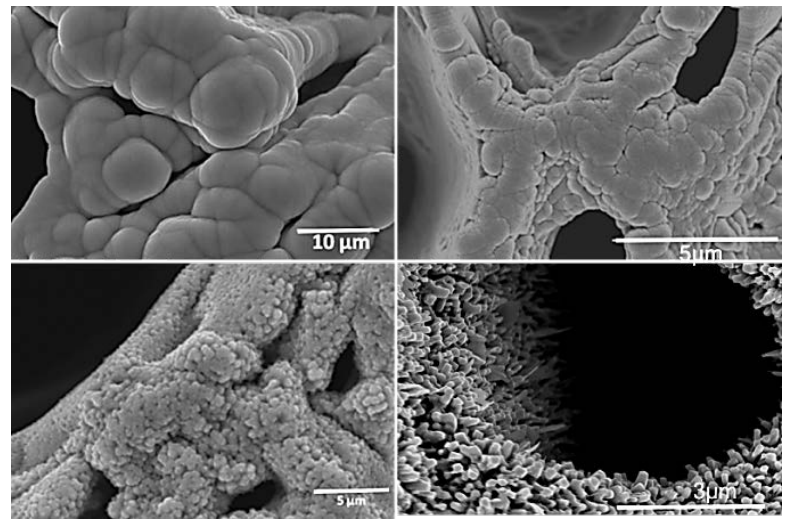

Figure 7. SEM analysis of $\mathrm{Nb}_{2} \mathrm{O}_{5} / \mathrm{BioC}$ composites deposited at different Substrate temperatures: a) $500{ }^{\circ} \mathrm{C}$, b) $600^{\circ} \mathrm{C}$, c) $900{ }^{\circ} \mathrm{C}$, d) $1000{ }^{\circ} \mathrm{C}$
The electrochemical characterization of the samples was performed by cyclic voltammetry measurements at different scan rates and is displayed in Figure 8. The curves show that both faradaic and non-faradaic processes contribute to the charge storage, where the pseudocapacitance is ascribed to the $\mathrm{Nb}_{2} \mathrm{O}_{5}$ layer, which was estimated to be in the range of 5 w.t \% from TG/DTA analysis. There are two main mechanisms involved in the electrochemical energy store in supercapacitors applications: (i) Electrochemical double-layer capacitance (EDLC), related to the electrostatic depletion of oppositely charged species accumulated between the electrolyte and the electrode material, and (ii) pseudo-capacitance or faradaic electrochemical storage, which is originated from the weakly attached surface ions. The surface functional groups, defects and grain boundaries can serve as excellent redox centers for the charge storage reactions. ${ }^{36}$ However, typical redox couples of $\mathrm{Nb}_{2} \mathrm{O}_{5}$ could not be observed due to the limited range of voltage applied ( -1 to $0 \mathrm{~V}$ vs. Ag/AgCl), to avoid water electrolysis during the measurements.

The capacitance values of different $\mathrm{Nb}_{2} \mathrm{O}_{5} / \mathrm{BioC}$ combinations according to the $\mathrm{Nb}_{2} \mathrm{O}_{5}$ polymorph deposited is also shown. $\mathrm{Nb}_{2} \mathrm{O}_{5} / \mathrm{BioC}$ composites fabricated at the highest temperature showed the best performance. A specific capacitance of $15 \mathrm{~F} \cdot \mathrm{g}^{-1}$ was obtained for the BioCarbon substrate at $1 \mathrm{mV} \mathrm{s}$ ${ }^{1}$ accounting for the total electrode mass, while deposition of $\mathrm{Nb}_{2} \mathrm{O}_{5}$, on the same substrate increased capacitance up to 104 $\mathrm{F} \cdot \mathrm{g}^{-1}$.

It is well known that the pseudocapacitive contribution of a material is highly influenced by its crystal structure, as alignment along certain directions has led to higher specific capacitance compared to amorphous materials of the same composition due to an additional pseudocapacitive contribution. ${ }^{37} \mathrm{How}-$ ever, prior research does not indicate whether one particular phase of $\mathrm{Nb}_{2} \mathrm{O}_{5}$ is better than another. 

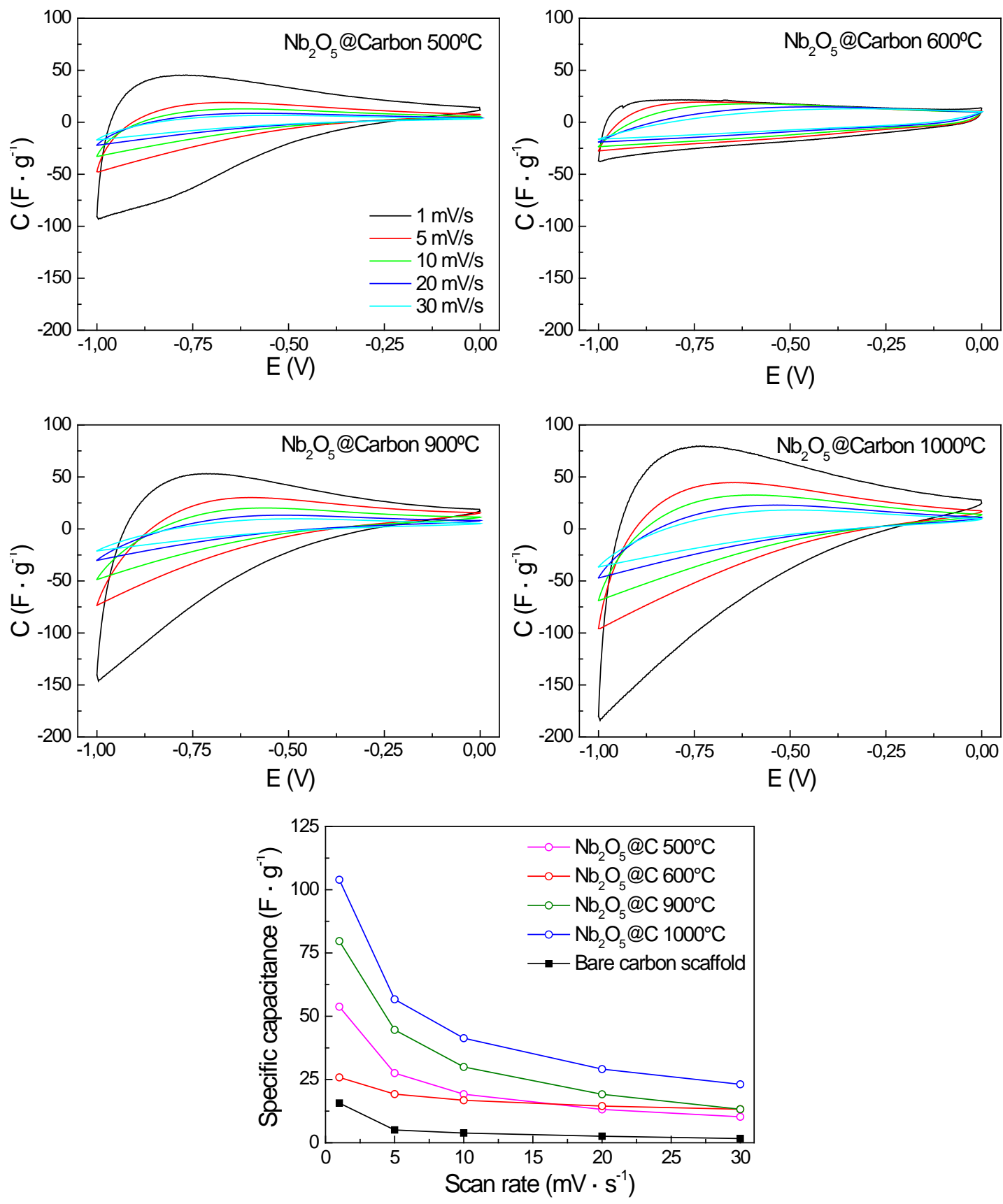

Figure 8. Cyclovoltammetry curves of $\mathrm{Nb}_{2} \mathrm{O}_{5} / \mathrm{BioC}$ composite materials synthesized at different process temperatures measured at different scan rates, and specific capacitance calculated by applying the formula: $C=\frac{\left(I_{\max }+I_{\min } \mid\right) / 2}{V m}$, where $I_{\max }$ and $I_{\min }$ are the intensity values at the curve edge, $V$ is the scan rate, while $m$ is the total mass of the electrode material $\left(\mathrm{Nb}_{2} \mathrm{O}_{5} / \mathrm{BioC}\right)$.

While the pseudohexagonal phase of $\mathrm{Nb}_{2} \mathrm{O}_{5}\left(\mathrm{TT}-\mathrm{Nb}_{2} \mathrm{O}_{5}\right)$ is preferred in electrochromic applications, the tetragonal phase (M$\mathrm{Nb}_{2} \mathrm{O}_{5}$ ) has shown the best performance when integrated in the electrode materials for lithium ion batteries. ${ }^{38}$ Recently, the orthorhombic phase $\left(\mathrm{T}-\mathrm{Nb}_{2} \mathrm{O}_{5}\right)$ has been reported to exhibit the so called intercalation pseudocapacitance, in which the crystalline network of $\mathrm{T}-\mathrm{Nb}_{2} \mathrm{O}_{5}$ offers transport pathways where the structural change upon intercalation is insignificant. ${ }^{13} \mathrm{Ab}$ initio molecular dynamics simulations were performed to compare the pseudocapacitor behavior in orthorhombic and monoclinic $\mathrm{Nb}_{2} \mathrm{O}_{5}\left(\mathrm{H}-\mathrm{Nb}_{2} \mathrm{O}_{5}\right)$ phases. The monoclinic phase is more struc- turally ordered than the orthorhombic and leads to 2D interconnected channels inside the structure in contrast to the $1 \mathrm{D}$ channels simulated for the orthorhombic one. ${ }^{39}$ However, there is still little fundamental understanding of the pseudocapacitive effect, which can be also ascribed to (i) the electrochemical adsorption of cations at the surface through charge transfer processes, (ii) to the intercalation of cations into interlayer gaps (van der Walls interaction) of a layered material, and (iii) to the typical redox reactions that result in changes of composition and phase like in conventional batteries. Furthermore, the size of the ion present in the electrolyte plays also a significant role in the charge storage process. Therefore, the enhanced capacitance 
observed in the $\mathrm{Nb}_{2} \mathrm{O}_{5} \mathrm{NRs} / \mathrm{BioC}$ composites with monoclinic structure could be ascribed to the increased non-faradaic capacitance surface area of the nanorods and its crystal structure.

\section{CONCLUSIONS}

Chemical vapor deposition of new niobium precursors on biomorphic carbon allowed nanocomposites consisting of conformal deposits of Nb2O5 thin films on conductive mesoporous matrices of biomorphic carbon. Morphology, crystallinity and phase composition of $\mathrm{Nb}_{2} \mathrm{O}_{5}$ deposits could be controlled by judicious choice of the CVD parameters combining high conductivity of the matrix with superior electrochemical properties of nanostructured niobium pentoxide. Electrochemical properties of $\mathrm{Nb}_{2} \mathrm{O}_{5} @ \mathrm{Bio}-\mathrm{C}$ confirmed the superior performance of nanocomposites, when compared to pure niobium oxides and corroborated the viability of the CVD process to uniformly coat substrates with complex architectures. Cyclovoltammetry measurements showed that amounts of $\mathrm{Nb}_{2} \mathrm{O}_{5}$ as low as $5 \%$ contributed towards an enhancement of the overall capacities from 15 to $104 \mathrm{~F} \mathrm{~g}^{-1}$, where the dramatic improvement in capacitance stems from the intercalation pseudocapacitance of the $\mathrm{Nb}_{2} \mathrm{O}_{5}$ coating with nanostructured thin films of monoclinic $\mathrm{Nb}_{2} \mathrm{O}_{5}$ nanorods delivering the best performance.

\section{ASSOCIATED CONTENT}

Supporting Information. This material is available free of charge via the Internet at http://pubs.acs.org.

\section{AUTHOR INFORMATION}

\section{Corresponding Author}

* E-mail: sanjay.mathur@uni-koeln.de

\section{Funding Sources}

Authors acknowledge the University of Cologne and the European Commission for supporting this activity in the framework of the SOLAROGENIX Project (EC-FP7- Grant Agreement No. 214281) for the financial support.

\section{ACKNOWLEDGMENT}

Authors gratefully acknowledge the University of Cologne for infrastructural support. A. G-P and J.R-R are grateful to the Junta de Andalucía for funding part of this work through project PE2012TEP862. Authors also thank Lluís López Conesa, who performed the HR-TEM cross section analyses and the TEM facilities at CCiT-UB and Laboratorio de Microscopias Avanzadas - Instituto de Nanociencia de Aragon (LMA-INA) are also acknowledged.

\section{REFERENCES}

1. Furukawa, S.; Ohno, Y.; Shishido, T.; Teramura, K.; Tanaka, T. Selective Amine Oxidation Using $\mathrm{Nb}_{2} \mathrm{O}_{5}$ Photocatalyst and $\mathrm{O}_{2}$. ACS Catal. 2011, 1, 1150-1153.

2. Furukawa, S.; Tamura, A.; Shishido, T.; Teramura, K.; Tanaka, T. Solvent-Free Aerobic Alcohol Oxidation using $\mathrm{Cu} / \mathrm{Nb}_{2} \mathrm{O}_{5}$ : Green and Highly Selective Photocatalytic System. Appl. Catal. B Environ. 2011, 110, 216-220.

3. Shishido, T.; Miyatake, T.; Teramura, K.; Hitomi, Y.; Yamashita, H.; Tanaka, T. Mechanism of Photooxidation of Alcohol over $\mathrm{Nb}_{2} \mathrm{O}_{5}$. J. Phys. Chem. C 2009, 113, 18713-18718.
4. Chambon, L.; Maleysson, C.; Pauly, A.; Germain, J. P.; Demarne, V.; Grisel, A. Investigation, for $\mathrm{NH}_{3}$ Gas Sensing Applications, of the $\mathrm{Nb}_{2} \mathrm{O}_{5}$ Semiconducting Oxide in the Presence of Interferent Species such as Oxygen and Humidity. Sens. Actuators, B 1997, 45, 107-114.

5. Fiz, R.; Hernandez-Ramirez, F.; Fischer, T.; Lopez-Conesa, L.; Estrade, S.; Peiro, F.; Mathur, S. Synthesis, Characterization, and Humidity Detection Properties of $\mathrm{Nb}_{2} \mathrm{O}_{5}$ Nanorods and $\mathrm{SnO}_{2} / \mathrm{Nb}_{2} \mathrm{O}_{5}$ Heterostructures. J. Phys. Chem. C 2013, 117, 10086-10094.

6. Chambon, L.; Pauly, A.; Germain, J. P.; Maleysson, C.; Demarne, V.; Grisel, A. A Model for the Responses of $\mathrm{Nb}_{2} \mathrm{O}_{5}$ Sensors to $\mathrm{CO}$ and $\mathrm{NH}_{3}$ Gases. Sens. Actuators, B 1997, 43, 60-64.

7. Wang, Z.; Hu, Y.; Wang, W.; Zhang, X.; Wang, B.; Tian, H.; Wang, Y.; Guan, J.; Gu, H. Fast and Highly-Sensitive Hydrogen Sensing of $\mathrm{Nb}_{2} \mathrm{O}_{5}$ Nanowires at Room Temperature. Int. J. Hydrogen Energy 2012, 37, 4526-4532.

8. Yao, D. D.; Rani, R. A.; O’Mullane, A. P.; Kalantar-zadeh, K.; Ou, J. Z. High Performance Electrochromic Devices Based on Anodized Nanoporous $\mathrm{Nb}_{2} \mathrm{O}_{5}$. J. Phys. Chem. C 2014, 118, 476 481.

9. Ou, J. Z.; Rani, R. A.; Ham, M.-H.; Field, M. R.; Zhang, Y.; Zheng, H.; Reece II, P.; Zhuiykov, S.; Sriram, S.; Bhaskaran, M.; Kaner, R. B.; Kalantar-zadeh, K. Elevated Temperature Anodized $\mathrm{Nb}_{2} \mathrm{O}_{5}$ : A Photoanode Material with Exceptionally Large Photoconversion Efficiencies. ACS Nano 2012, 6, 4045-4053.

10. Luo, H.; Song, W.; Hoertz, P. G.; Hanson, K.; Ghosh, R.; Rangan, S.; Brennaman, M. K.; Concepcion, J. J.; Binstead, R. A.; Bartynski, R. A.; Lopez, R.; Meyer, T. A Sensitized $\mathrm{Nb}_{2} \mathrm{O}_{5}$ Photoanode for Hydrogen Production in a Dye-Sensitized Photoelectrosynthesis Cell. J. Chem. Mater. 2013, 25, 122-131.

11. Le Viet, A.; Jose, R.; Reddy, M. V; Chowdari, B. V. R.; Ramakrishna, S. $\mathrm{Nb}_{2} \mathrm{O}_{5}$ Photoelectrodes for Dye-Sensitized Solar Cells: Choice of the Polymorph. J. Phys. Chem. C 2010, 114, 21795-21800.

12. Chandiran, A.K.; Nazeeruddin, M.K.; Grätzel, M. The Role of Insulating Oxides in Blocking the Charge Carrier Recombination in Dye-Sensitized Solar Cells. Adv. Func. Mater 2014, 24, 16151623.

13. Augustyn, V.; Come, J.; Lowe, M. A.; Kim, J. W.; Taberna, P.L.; Tolbert, S. H.; Abruña, H. D.; Simon, P.; Dunn, B. HighRate Electrochemical Energy Storage through $\mathrm{Li}^{+}$Intercalation Pseudocapacitance. Nat. Mater. 2013, 12, 518-522.

14. Tamang, R.; Varghese, B.; Mhaisalkar, S. G.; Tok, E. S.; Sow, C. H. Probing the Photoresponse of Individual $\mathrm{Nb}_{2} \mathrm{O}_{5}$ Nanowires with Global and Localized Laser Beam Irradiation. Nanotechnology 2011, 22, 115202.

15. Venkataraj, S.; Drese, R.; Liesch, Ch.; Kappertz, O.; Jayavel, R.; Wuttig, M. Temperature Stability of Sputtered Niobium-Oxide Films. J. Appl. Phys. 2002, 91, 4863-4871.

16. Jang, J.-H.; Kim, T.-Y.; Kim, N.-J.; Lee, C.-H.; Park, E.-M.; Park, C.; Suh, S.-J. Preparation and Characterization of $\mathrm{Nb}_{2} \mathrm{O}_{5}-$ $\mathrm{Al}_{2} \mathrm{O}_{3}$ Composite Oxide Formed by Cathodic Electroplating and Anodizing. Mater. Sci. Eng. B 2011, 176, 1505-1508.

17. Lim, J. H.; Choi, J. Formation of Niobium Oxide Nanowires by Thermal Oxidation. J. Ind. Eng. Chem. 2009, 15, 860-864.

18. Avellaneda, C. O.; Pawlicka, A.; Aegerter, M. A. Two Methods of Obtaining Sol-Gel $\mathrm{Nb}_{2} \mathrm{O}_{5}$ Thin Films for Electrochromic Devices. J. Mater. Sci. 1998, 33, 2181-2185.

19. Barros Filho, D. D. A.; Abreu Filho, P. P.; Werner, U.; Aegerter, M. A. Photoelectrochemical Properties of Sol-Gel $\mathrm{Nb}_{2} \mathrm{O}_{5}$ Films. J. Sol-Gel Sci. Technol. 1997, 8, 735-742.

20. Özer, N.; Chen, D.-G.; Lampert, D. M. Preparation and Properties of Spin-Coated $\mathrm{Nb}_{2} \mathrm{O}_{5}$ Films by the Sol-Gel Process for Electrochromic Applications. Thin Solid Films 1996, 277, 162168.

21. Miyake, H.; Kozuka, H. Photoelectrochemical Properties of $\mathrm{Fe}_{2} \mathrm{O}_{3}-\mathrm{Nb}_{2} \mathrm{O}_{5}$ Films Prepared by Sol-Gel Method. J. Phys. Chem. B 2005, 109, 17951-17956. 
22. Aegerter, M. A. Sol-Gel Niobium Pentoxide: a Promising Material for Electrochemical Coatings, Batteries, Nanocrystalline Solar Cells and Catalysis. Sol. Energy Mater. Sol. Cells 2001, 68, 401-422.

23. O’Neill, S. A.; Parkin, I. P.; Clark, R. J. H.; Mills, A.; Elliott, N. Atmospheric Pressure Chemical Vapour Deposition of Thin Films of $\mathrm{Nb}_{2} \mathrm{O}_{5}$ on Glass. J. Mater. Chem. 2003, 13, 2952-2956.

24. Kukli, K.; Ritala, M.; Leskelä, M.; Lappalainen, R. Niobium Oxide Thin Films Grown by Atomic Layer Epitaxy. Chem. Vap. Depos. 1998, 29-34.

25. Viswanathamurthi, P.; Bhattarai, N.; Kim, H. Y.; Lee, D. R.; Kim, S. R.; Morris, M. A. Preparation and Morphology of Niobium Oxide Fibres by Electrospinning. Chem. Phys. Lett. 2003, 374, 79-84.

26. Sieber, I.; Hildebrand, H.; Friedrich, A.; Schmuki, P. Formation of Self-Organized Niobium Porous Oxide on Niobium. Electrochem. Commun. 2005, 7, 97-100.

27. de Arruda Rodrigues, C.; de Tacconi, N. R.; Chanmaee, W.; Rajeswhar, K. Cathodic Electrosynthesis of Niobium Oxide OneDimensional Nanostructures with Tailored Dimensions. Electrochem. Solid-State Lett. 2010, 13, B69-B72.

28. Varghese, B.; Haur, S. C.; Lim, C.-T. $\mathrm{Nb}_{2} \mathrm{O}_{5}$ Nanowires as Efficient Electron Field Emitters. J. Phys. Chem. C 2008, 112, 10008-10012.

29. Luo, H.; Wei, M.; Wei, K. Synthesis of $\mathrm{Nb}_{2} \mathrm{O}_{5}$ Nanosheets and its Electrochemical Measurements. Mater. Chem. Phys. 2010, 120, 6-9.

30. Wei, M.; Qi, Z.; Ichihara, M.; Zhou, H. Synthesis of SingleCrystal Niobium Pentoxide Nanobelts. Acta Mater. 2008, 56, 2488-2494.

31. Appel, L.; Fiz, R.; Tyrra, W.; Mathur, S. New Iso-Propoxides, Tert-Butoxides and Neo-Pentoxides of Niobium (V): Synthesis, Structure, Characterization and Stabilization by Trifluoroheteroarylalkenolates and Pyridine Ligands. Dalton Trans. 2012, 41, 1981-1990.
32. Mathur, S.; Sivakov, V.; Shen, H.; Barth, S.; Cavelius, C.; Nilsson, A.; Kuhn, P. Nanostructured Films of Iron, Tin and Titanium Oxides by Chemical Vapor Deposition. Thin Solid Films 2006, 502, 88-93.

33. Gutiérrez-Pardo, A.; Ramírez-Rico, J.; de Arellano-López, A. R.; Martínez-Fernández, J. Characterization of Porous Graphitic Monoliths from Pyrolyzed Wood. J. Mater. Sci. 2014, 49, 7688-7696.

34. Brückmann, L.; Tyrra, W.; Stucky, S.; Mathur, S. Novel Air-Stable and Volatile Bis(pyridylalkenolato)palladium(II) and -platinum(II) Derivatives. Inorg. Chem. 2012, 51, 536-542.

35. Giebelhaus, I.; Müller, R.; Tyrra, W.; Pantenburg, Fischer, T; Mathur, S. First Air Stable Tin (II) $\beta$-Heteroarylalkenolate: Synthesis, Characterization and Application in Chemical Vapor Deposition. Inorg. Chim. Acta 2011, 372, 340-346.

36. Zhi, M.; Xiang, C.; Li, J.; Li, M.; Wu, N. Nanostructured Carbon-Metal Oxide Composite Electrodes for Supercapacitors: a Review. Nanoscale 2013, 5, 72-88.

37. Brezesinski, K.; Wang, J.; Haetge, J.; Reitz, C.; Steinmueller, S. O.; Tolbert, S. H.; Smarsly, B. M.; Dunn, B.; Brezesinski, T. Pseudocapacitive Contributions to Charge Storage in Highly Ordered Mesoporous Group V Transition Metal Oxides with IsoOriented Layered Nanocrystalline Domains. J. Am. Chem. Soc. 2010, 132, 6982-6990.

38. Le Viet, A.; Reddy, M. V.; Jose, R.; Chowdari, B. V. R.; Ramakrishna, S. Nanostructured $\mathrm{Nb}_{2} \mathrm{O}_{5}$ Polymorphs by Electrospinning for Rechargeable Lithium Batteries. J. Phys. Chem. C 2010, 114, 664-671.

39. Lubimtsev, A. A.; Kent, P. R. C.; Sumpter, B. G.; Ganesh, P. Understanding the Origin of High-Rate Intercalation Pseudocapacitance in $\mathrm{Nb}_{2} \mathrm{O}_{5}$ Crystals. J. Mater. Chem. A 2013, 1, 14951-14956. 